\section{Spatial heterogeneity of soil respiration in a seasonal rainforest with complex terrain}

\author{
Qing-Hai Song ${ }^{(1-3)}$, Zheng-Hong Tan ${ }^{(1-2)}$, Yi-Ping Zhang ${ }^{(1)}$, Min Cao ${ }^{(1)}$, \\ Li-Qing Sha ${ }^{(1)}$, Yong Tang ${ }^{(1)}$, Nai-Shen Liang ${ }^{(2)}$, Douglas Schaefer ${ }^{(2)}$, \\ Jun-Fu Zhao ${ }^{(1-3)}$, Jun-Bin Zhao ${ }^{(1-3)}$, Xiang Zhang ${ }^{(1-3)}$, Lei Yu ${ }^{(1-3)}$, \\ Xiao-Bao Deng ${ }^{(1)}$
}

\begin{abstract}
Although numerous studies have been conducted to investigate ecosystem-scale soil respiration, our understanding of this process is still incomplete, especially with respect to the spatial variability and ecological factors that drive such variability in respiration. The present study was conducted to investigate the respiration, structural parameters and soil properties in a seasonal rainforest with complex topography. Specifically, we sampled a 20-ha plot in intervals of $20 \mathrm{~m}$ to measure the soil respiration. Based on the entire 20-ha plot, the spatial mean soil respiration rate was $4.09 \mu \mathrm{mol} \mathrm{m}^{-2} \mathrm{~s}^{-1}$ and $2.71 \mu \mathrm{mol}$ $\mathrm{m}^{-2} \mathrm{~s}^{-1}$ during the rainy and dry season, respectively. Strong spatial heterogeneity was observed, with coefficients of variance of $42 \%$ and $38 \%$ being obtained for the rainy and dry season, respectively. The patch size of soil respiration was approximately $40 \mathrm{~m}$, which was much smaller than that of the soil temperature and water content. Soil-respiration hot spots induced a rightskewed probability density function of soil respiration in space. However, termite mounds did not account for the respiration hot spots. The required number of sampling points in our studied forest was estimated to be 71 and 51 for the rainy and dry season, respectively.
\end{abstract}

Keywords: Semivariance, Soil Physical and Chemical Properties, Soil-respiration Hot Spots, Stand Structure

\section{Introduction}

Soil respiration refers to the flux of root and microbially respired $\mathrm{CO}_{2}$ from the soil to the atmosphere. Soil respiration is a key ecological process that makes ecosystem carbon cycling possible. Soil respiration has been studied for approximately one century (Lun-

(1) Key Laboratory of Tropical Forest Ecology, Xishuangbanna Tropical Botanical Garden, Chinese Academy of Sciences, Menglun, 666303 Yunnan (China); (2) Center for Global Environmental Research, National Institute for Environmental Studies, Tsukuba, 305-8506 Ibaraki (Japan); (3) University of Chinese Academy of Sciences, 100039 Beijing (China)

@ Zheng-Hong Tan (tanzh@xtbg.ac.cn)

Received: Jul 10, 2012 - Accepted: Jan 14, 2013

Citation: Song Q-H, Tan Z-H, Zhang Y-P, Cao $M$, Sha L-Q, Tang $Y$, Liang N-S, Schaefer D, Zhao J-F, Zhao J-B, Zhang X, Yu L, Deng X$B, 2013$. Spatial heterogeneity of soil respiration in a seasonal rainforest with complex terrain. iForest 6: 65-72 [online 2013-02-07] URL: http://www.sisef.it/ iforest/contents/?id=ifor0681-006

Communicated by: Roberto Tognetti degårdh 1927); however, there has been growing concern about soil respiration in recent years (Raich \& Schlesinger 1992, Bond-Lamberty \& Thomson 2010). Indeed, soil respiration is the second largest terrestrial carbon flux, following photosynthesis. Accordingly, small changes in soil respiration will have strong effects on atmospheric $\mathrm{CO}_{2}$ concentration and climate warming. Although numerous studies have been carried out to investigate ecosystem soil respiration, our understanding of it is still limited, especially regarding its spatial variability and related ecological factors.

Most previous studies of soil respiration have tracked temporal variation in one or several small plots. Microclimatic variables (e.g., soil temperature and water content) usually explain most of the observed temporal variation (Davidson et al. 1998). However, neither soil temperature nor water content can completely account for the spatial variability of soil respiration (e.g., Yim et al. 2003, Sotta et al. 2004, Tedeschi et al. 2006). Soil respiration shows strong heterogeneity at scales from plants to landscapes (Stoyan et al. 2000, Euskirchen et al. 2003), and its environmental drivers have been found to vary with the experimental design and goals of various studies (Adachi et al. 2009). Hanson et al. (1993) regarded topo- graphy as the main factor involved in induction of spatial variation of soil respiration. Measurements in a Canadian boreal forest partly supported this idea and suggested that soil substrate should also be taken into account (Rayment \& Jarvis 2000). Some studies have emphasized the significance of canopy structure (e.g., root biomass, tree distance, and litter fall amount) on spatial patterns of soil respiration (Søe \& Buchmann 2005, Katayama et al. 2009). Soil microbes and fauna (e.g., earthworms and termites) have also been found to influence the spatial variability of soil respiration (Xu \& Qi 2001, Ohashi et al. 2007).

Most of the aforementioned studies were conducted in relatively homogenous forests with flat terrain. In this study, we conducted a large-scale (20 ha) series of soil-respiration measurements in a strongly seasonal tropical rain forest with complex topography. Related biotic and abiotic factors, such as the tree mean diameter at breast height (DBH), total root mass $\left(\mathrm{M}_{\text {root }}\right)$, litter fall production $\left(\mathrm{M}_{\mathrm{lf}}\right)$, soil water content at $5 \mathrm{~cm}\left(\mathrm{M}_{\mathrm{s}-5}\right)$, and soil temperature at $5 \mathrm{~cm}\left(\mathrm{~T}_{\mathrm{s}-5}\right)$, were also measured to explain the spatial pattern of soil respiration. We expect soil respiration to be strongly spatially heterogeneous in tropical rainforests and that this heterogeneity will be explained by biotic or abiotic factors. The specific objectives of this study were: (1) to provide a large quantity of assessments of spatial heterogeneity; and (2) to identify the factors that drive the spatial patterns of soil respiration.

\section{Methods}

\section{Site description}

This study was carried out in a 20 -ha permanent plot $(400 \mathrm{~m}$ [north-south] $\times 500 \mathrm{~m}$ [east-west] - Fig. 1) of tropical rainforest in the Xishuangbanna Natural Reserve $\left(101^{\circ}\right.$ 34' 26"-47” E, 21 36' 42"-58” N), Yunnan, China. The plot establishment, including topographic mapping (using electronic wholestation theodolites), corner-post setting, and an initial tree census (adopting the techniques developed by the Center for Tropical Forest Science), was started in April 2006 and completed in June 2007. The mean elevation of the plot was $760 \mathrm{~m}$, ranging from $710 \mathrm{~m}$ to $860 \mathrm{~m}$. Three small streams pass through the plot.

The climate is dominated by the Indian monsoon cycle. The mean annual air temperature is $21.8^{\circ} \mathrm{C}$, and the total annual rainfall is $1493 \mathrm{~mm}$, approximately $87 \%$ of which occurs during the rainy season (May to October - Tan et al. 2010).

The soil in the study area is an oxisol derived from sandstone. The organic matter content of the $0-20 \mathrm{~cm}$ mineral soil layer is approximately $20 \mathrm{~g} \mathrm{~kg}^{-1}$. 
Fig. 1 - The topography of the 20ha plot in $\mathrm{Bu}-$ beng, Xishuangbanna, China.

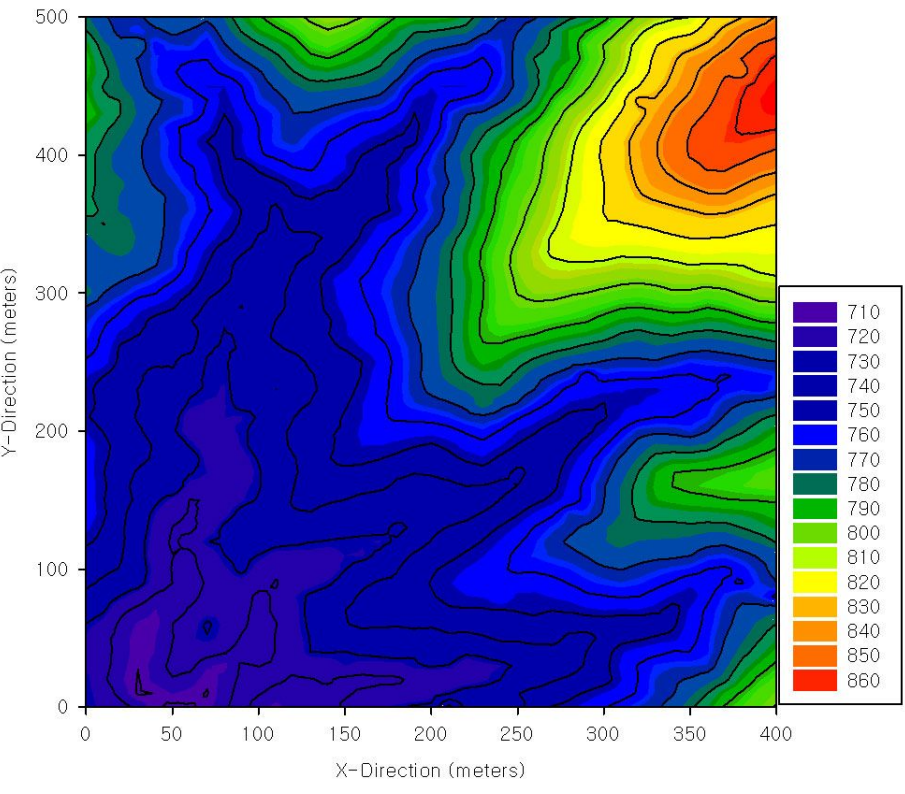

The primary vegetation in this area consists of a tropical seasonal rainforest. The forest profile can be divided into five layers. The main layer $(>45 \mathrm{~m}$ tall) is dominated by Parashorea chinensis H. Wang of the Dipterocarpaceae. The 30-45 m layer is dominated by Sloanea tomentosa (Benth.) Rehd. $\&$ E. H. Wils., Pometia tomentosa (Bl.) Teysm. \& Binn., and Semecarpus reticulata Lecte. The $20-30 \mathrm{~m}$ canopy layer is primarily composed of Garciniacowa Roxb., Ficus langkokensis Drake, and Pseuduvaria indochinensis Merr. Baccaurea ramiflora Lour, while Dichapetalum gelonioides (Roxb.) Engl. dominates the understory $(10-20 \mathrm{~m})$. The 5-10 m layer is mainly composed of Pittosporopsis kerrii Craib, Mezzettiopsis creaghii Ridl., Saprosma ternata, Leea compactiflora Kurz, Phoebe lanceolata (Nees) Nees, and Syzygium megacarpum (Craib) Rathakr. \& N.C. Nair (Cao et al. 2008). The number of individuals decreased as the DBH increased. Nearly 70000 individuals (approximately $73 \%$ of the total) were in the size class of $1-5 \mathrm{~cm}$. Parashorea chinensis $\mathrm{H}$. Wang ranked second in terms of abundance ( $8.29 \%$ of individuals) and first in the basal area $\left(5.68 \mathrm{~m}^{2} \mathrm{ha}^{-1}\right)$ in the plot.

\section{Soil physical and chemical properties}

We divided our $400 \times 500-\mathrm{m}$ plot into grids of $30 \times 30 \mathrm{~m}$, and the 252 generated nodes were considered base points. Together with each base point, two additional sampling points were located at random combinations of 2 and $5 \mathrm{~m}, 2$ and $15 \mathrm{~m}$, and 5 and $15 \mathrm{~m}$ along a random compass bearing away from the associated base point. We sampled $500 \mathrm{~g}$ of topsoil $(0-10 \mathrm{~cm})$ from each sample point and a total of 756 samples were collected. All soil samples were sent to the Central Lab of Xishuangbanna Tropical Botanical Gar- den at the Chinese Academy of Sciences for chemical and physical analysis.

The $\mathrm{pH}$ levels were measured in fresh soil. Briefly, a small sample of soil was collected, and an indicator solution was added to form a paste. The paste was then coated with barium sulfate powder, which changes colour depending on the $\mathrm{pH}$ of the soil, and the colours of the powder were compared with a colour chart. The soil samples were subsequently air-dried, crushed, sieved, and packaged for later additional analysis. The corer method was used to determine the soil bulk density (Arshad et al. 1996). The soil carbon level was measured using the $\mathrm{H}_{2} \mathrm{SO}_{4}$ $\mathrm{K}_{2} \mathrm{Cr}_{2} \mathrm{O}_{7}$ oxidation method (Nelson \& Sommers 1996). The total nitrogen content was measured using the Micro-Kjeldahl method (Ma \& Zuazaga 1942), while the available nitrogen was estimated using the micro-diffusion method (Saghir et al. 1993). The total phosphorus and potassium levels were measured using an inductively coupled plasma atomic-emission spectrometer (Thermo Jarrell Ash Co., Franklin, USA) and $\mathrm{HNO}_{3}$ $\mathrm{HClO}_{4}$ soil solution (Allen 1989). The level of available phosphorus was estimated colorimetrically based on a $0.03 \mathrm{~mol} \mathrm{l}^{-1} \mathrm{NH}_{4} \mathrm{~F}$ and $0.025 \mathrm{~mol} \mathrm{l}^{-1} \mathrm{HCl}$ soil solution (Allen 1989). The available potassium was extracted from a neutral $1 \mathrm{~mol} \mathrm{l}^{-1} \mathrm{CH}_{3} \mathrm{COONH}_{4}$ solution analysis using the same method as that used for total potassium (Allen 1989).

\section{Stand structural parameters}

The DBH of all of the trees was measured and used to calculate the mean DBH of each subplot. We estimated the root biomass using site-specific allometric equations with DBH as an entry variable (Tan et al. 2010). Litterfall was collected with 151 litter traps $(1 \times 1 \mathrm{~m}$ - placed near the soil-respiration measurement points). Litterfall was collected biweekly for approximately 2 years.

\section{Soil respiration}

The soil respiration was measured using a Li-6400 system (Li-Cor Inc., Lincoln, NE, USA), which consisted of an infrared gas analyser and a portable soil chamber ( $\mathrm{Li}-$ 6400-09) with a diameter of $9.5 \mathrm{~cm}$. A polyvinyl chloride collar (diameter of $10.4 \mathrm{~cm}$ and height of $7.0 \mathrm{~cm}$ ) was installed in the forest floor to a depth of $\sim 4 \mathrm{~cm}$. Leaf litter and small branches were left in the collar, while coarse woody debris was removed. The measurements were replicated three times at each sampling point and data collected from 09:00 to 14:00 local time was taken to represent respiration in that day (Sha et al. 2005, Yao et al. 2011). Two groups with the same instruments carried out the field work simultaneously to reduce the time required for the field investigation. The soil water content and soil temperature were measured at depths of $5 \mathrm{~cm}$ at the same time using a conductivity probe (Theta probe MPM160B, ICT International Pty Ltd., Armidale, New South Wales, Australia) and a penetration probe inserted into the soil in the vicinity of the collar.

On July $7^{\text {th }} 2010$, we started the first field campaign to measure soil respiration during the rainy season. A total of 151 of the 500 subplots were selected for soil-respiration measurements (Fig. S1). In each subplot, three collars were placed near the litter fall traps. A total of 453 points was sampled; however, because the soil water content often exceeds the field capacity during the rainy season we did not measure the soil temperature and water content in this period. It should be noted that we encountered many termite mounds during the field work; however, none of the litter fall traps were located above a termite mound. Therefore, we selected eight typical large termite mounds for soil-respiration measurements and measured the respiration at 17 points above the selected termite mound.

Several unexpected intensive rainfall events occurred in the 2011 dry season. On February $10^{\text {th }} 2012$, we started the second field campaign to measure soil respiration during the dry season using the same sampling design used for the rainy season. The diurnal range of temperature and water conditions in the dry season is higher than in the rainy season. To check whether temporal trends could affect the spatial pattern of soil respiration, we measured the temporal variation of the soil respiration, soil temperature and soil water content during the dry and rainy seasons. An automatic soil respirationmeasurement system developed by Dr. Naishen Liang of the National Institute of Environmental Studies was used to record the temporal patterns (Liang et al. 2004). 


\section{Statistics}

The definition of outliers in box plots was introduced to define soil-respiration hot spots in this study. Respiration values larger than the sum of the upper quartiles and 1.5 times the interquartile range were treated as hot spots.

We carried out geostatistical analysis to quantify the spatial structural variance and its range. Semivariance was calculated as follows (Robertson et al. 1993 - eqn. 1):

$$
\gamma(h)=\frac{1}{2 \mathrm{~N}} \sum_{i=1}^{N(h)}[y(i)-y(i+h)]^{2}
$$

where $y(i)$ is the value of the variable $y$ at point $i, y(i+h)$ is its value at a point at a distance $h$, and $N(h)$ is the number of observation points separated by the distance $h$. All data were fitted with a spherical model (eqn. 2):

$$
\left\{\begin{array}{ll}
\gamma(h)=C_{0}+C\left[\frac{3}{2}\left(\frac{h}{A_{0}}\right)-\frac{1}{2}\left(\frac{h}{A_{0}}\right)^{3}\right] & h<A_{0} \\
\gamma(h)=C_{0}+C_{\gamma} & h>A_{0}
\end{array}\right\}
$$

where $C_{0}$ is the nugget variance, $A_{0}$ is the range of variance, $C$ is the structural variability, $C_{0}+C$ is a constant, $h$ is the separation distance, and $\gamma$ is the semivariance.

All statistical analyses were conducted using the SPSS software (SPSS 13.0 Inc. Chicago, IL, USA). One-way analysis of variance (ANOVA) was used to identify differences in the soil respiration between the rainy and dry seasons. Multiple stepwise-regression was used to determine the contributions of different factors (e.g., soil temperature and water content) to the spatial differences in soil respiration. Principal component analysis (PCA) was used to reduce the number of parameters when several parameters reflected the same underlying process.

\section{Results}

When the entire 20-ha plot was considered, the spatial mean soil respiration was 4.09 $\mu \mathrm{mol} \mathrm{m} \mathrm{m}^{-2} \mathrm{~s}^{-1}$ during the rainy season, which was higher than the median value (3.82 $\left.\mu \mathrm{mol} \mathrm{m} \mathrm{m}^{-2} \mathrm{~s}^{-1}\right)$. This finding reflects the rightskewed probability density function (PDF) of this period (Fig. 2). The spatial mean value of the soil respiration $\left(2.71 \mu \mathrm{mol} \mathrm{m} \mathrm{m}^{-2}\right.$ $\left.\mathrm{s}^{-1}\right)$ was also higher than the median $(2.53$ $\mu \mathrm{mol} \mathrm{m}{ }^{-2} \mathrm{~s}^{-1}$ ) during dry season. The soil respiration differed significantly between the rainy and dry seasons (one-way ANOVA, $\mathrm{p}<0.001$ ). The skewness was 0.89 during rainy season and 1.27 in the dry season (Tab. 1). The PDF showed a normal pattern after logarithmic conversion in both seasons (Fig. 1 subplots), which allowed us to identify soil-efflux hot spots (values over $9.40 \mu \mathrm{mol}$ $\mathrm{m}^{-2} \mathrm{~s}^{-1}$ during the rainy season and $5.34 \mu \mathrm{mol}$ $\mathrm{m}^{-2} \mathrm{~s}^{-1}$ during the dry season). The PDF of the soil temperature and volumetric water
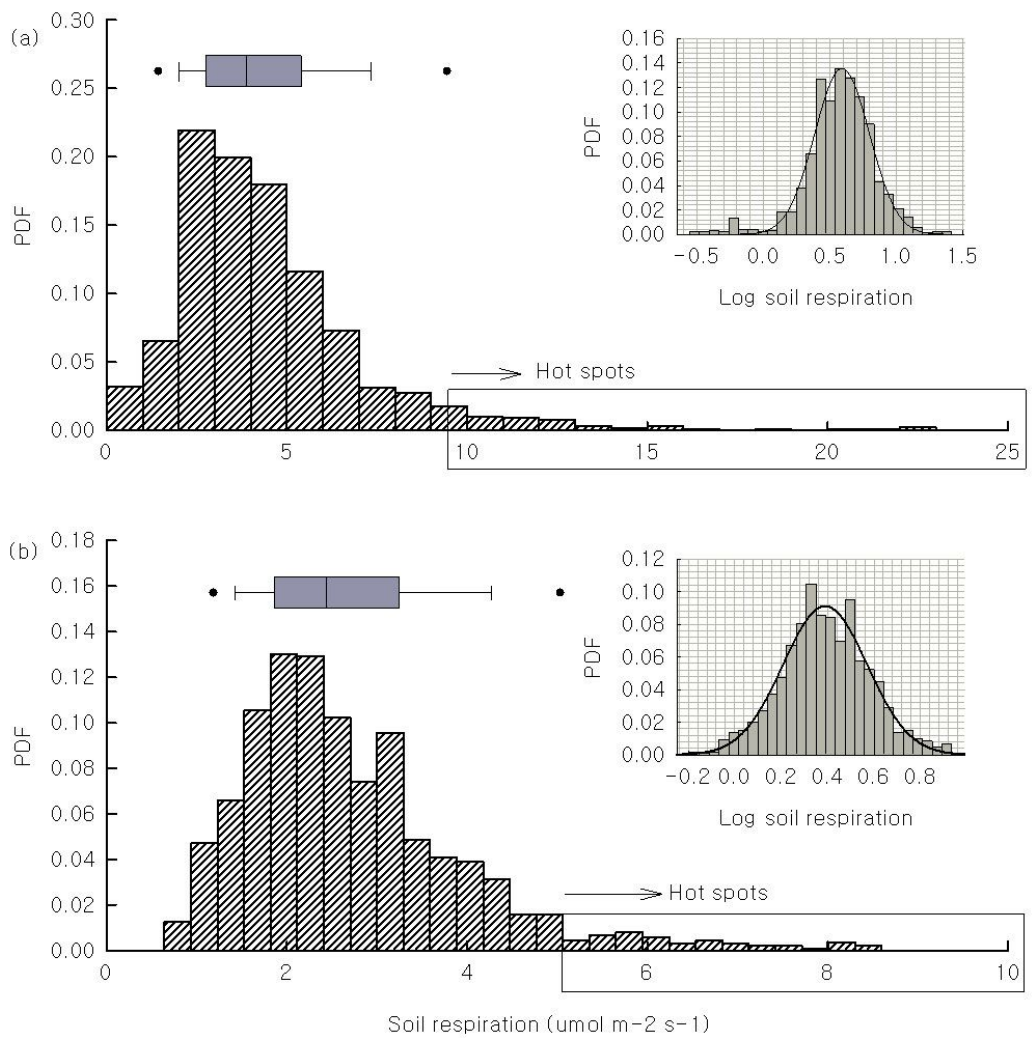

Fig. 2 - Probability density function (PDF) of the soil respiration in space during the rainy (a) and dry season (b) collected in a 20-ha plot tropical rain forest of Xishuangbanna, China. The black circles in the box plot indicate the statistical outliers. Values larger than the out liers (included in the rectangular box) are respiration hot spots. The right-upper subplot show the log transformed data fitted using a three-parameter Gaussian equation to illustrate a lognormal distribution.

Tab. 1 - Statistical parameters of soil respiration in the rainy season $\left(\mathrm{R}_{\mathrm{s}-\mathrm{rain}}\right)$ and in the dry season $\left(\mathrm{R}_{\mathrm{s}-\mathrm{dry}}\right)$, dry-season soil temperature at $5 \mathrm{~cm}\left(\mathrm{~T}_{\mathrm{s}-5}\right)$, soil water content at $5 \mathrm{~cm}\left(\mathrm{M}_{\mathrm{s}-5}\right)$, mean diameter at breast height $(\mathrm{DBH})$, total root mass $\left(\mathrm{M}_{\text {root }}\right)$, litterfall production $\left(\mathrm{M}_{\mathrm{lf}}\right)$, total carbon content (TC), total nitrogen content (TN), total phosphorus content (TP), total potassium content (TK), available phosphorus content (avP), available potassium content $(\mathrm{avK})$, available nitrogen content $(\mathrm{avN}), \mathrm{pH}$ value $(\mathrm{pH})$, and bulk density (BD). SD is the standard deviation; CV is the coefficient of variance; $\mathrm{n}$ is the number of samples. Soil respiration, temperature, and water content are expressed as $\mu \mathrm{mol} \mathrm{m} \mathrm{m}^{-2} \mathrm{~s}^{-1}$, ${ }^{\circ} \mathrm{C}$, and $\mathrm{m}^{3} \mathrm{~m}^{-3}$, respectively. $\mathrm{DBH}, \mathrm{M}_{\mathrm{root}}$, and $\mathrm{M}_{\mathrm{lf}}$ are reported as $\mathrm{cm}$, ton dry matter, and $\mathrm{g}$ dry matter, respectively. $\mathrm{TC}$, TN, TP, and TK are in $\mathrm{g} \mathrm{Kg}^{-1}$. avP, avK, and avN are expressed in $\mathrm{mg} \mathrm{Kg}^{-1}$. BD is in $\mathrm{g}$ $\mathrm{cm}^{-3}$.

\begin{tabular}{lcccccc}
\hline Parameter & Mean & SD & CV (\%) & Skewness & Kurtosis & n \\
\hline $\mathrm{R}_{\text {s-rain }}$ & 4.09 & 1.75 & 42.84 & 0.89 & 2.08 & 151 \\
$\mathrm{R}_{\text {s-dry }}$ & 2.71 & 1.04 & 38.58 & 1.27 & 2.09 & 151 \\
$\mathrm{~T}_{\text {s-5 }}$ & 16.35 & 1.32 & 8.11 & -0.29 & 0.4 & 151 \\
$\mathrm{M}_{\text {s-5 }}$ & 0.18 & 0.05 & 27.94 & 0.36 & -0.31 & 151 \\
$\mathrm{DBH}$ & 5.69 & 0.98 & 17 & 0.3 & -0.05 & 151 \\
$\mathrm{M}_{\text {root }}$ & 3.57 & 4.16 & 116.36 & 4.17 & 21.6 & 151 \\
$\mathrm{M}_{\mathrm{ff}}$ & 23.3 & 6.95 & 29.81 & 0.22 & -0.13 & 151 \\
$\mathrm{TC}$ & 18.38 & 5.3 & 28.82 & 2.38 & 13.42 & 756 \\
$\mathrm{TN}$ & 1.83 & 0.41 & 22.13 & 1.33 & 5.37 & 756 \\
$\mathrm{TP}$ & 0.34 & 0.1 & 29.06 & 1.13 & 2.4 & 756 \\
$\mathrm{TK}$ & 1.25 & 3.46 & 30.79 & 0.85 & 1.08 & 756 \\
$\mathrm{avP}$ & 4.89 & 6.27 & 128.17 & 5.37 & 41.13 & 756 \\
$\mathrm{avK}$ & 181.92 & 89.77 & 49.35 & 2.06 & 7.26 & 756 \\
$\mathrm{avN}$ & 180.16 & 41.23 & 22.88 & 1.48 & 6.17 & 756 \\
$\mathrm{pH}$ & 4.91 & 0.64 & 13.01 & 0.87 & 0.08 & 756 \\
$\mathrm{BD}$ & 1.13 & 0.12 & 10.74 & -0.17 & 1.29 & 756 \\
\hline
\end{tabular}



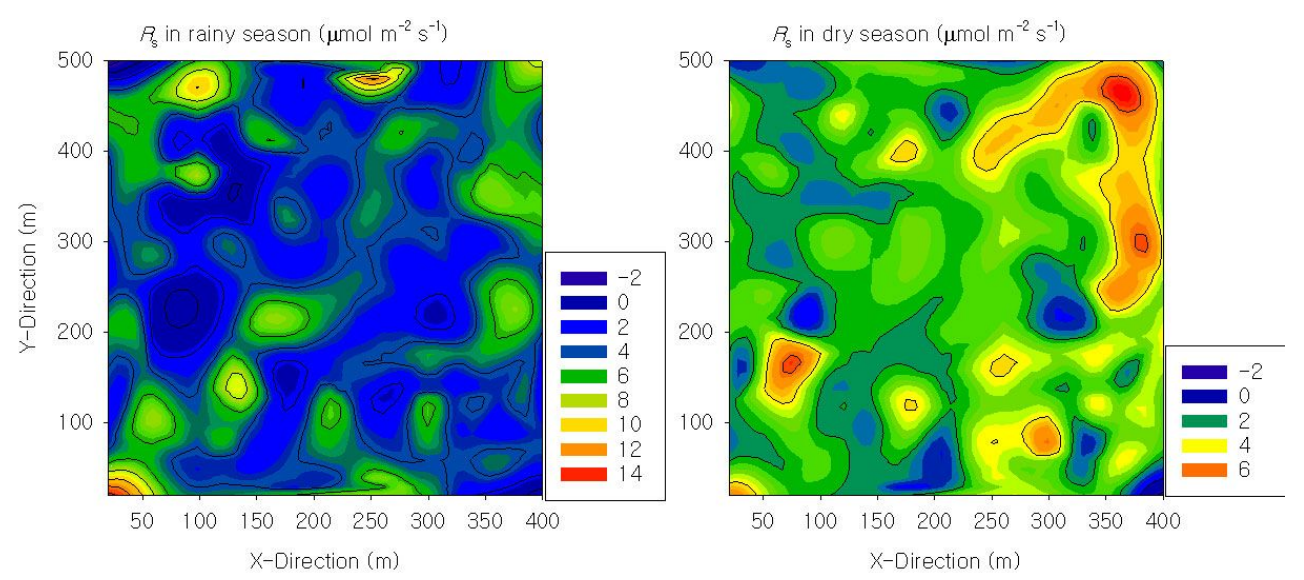

Fig. 3 - The contour map of the soil respiration $\left(R_{\mathrm{s}}\right)$ in the rainy season and in the dry season, soil temperature at $5 \mathrm{~cm}$, and soil water content at $5 \mathrm{~cm}$ collected with intervals of $20 \mathrm{~m}$ from a 20-ha tropical rainforest plot in Xishuangbanna, China.
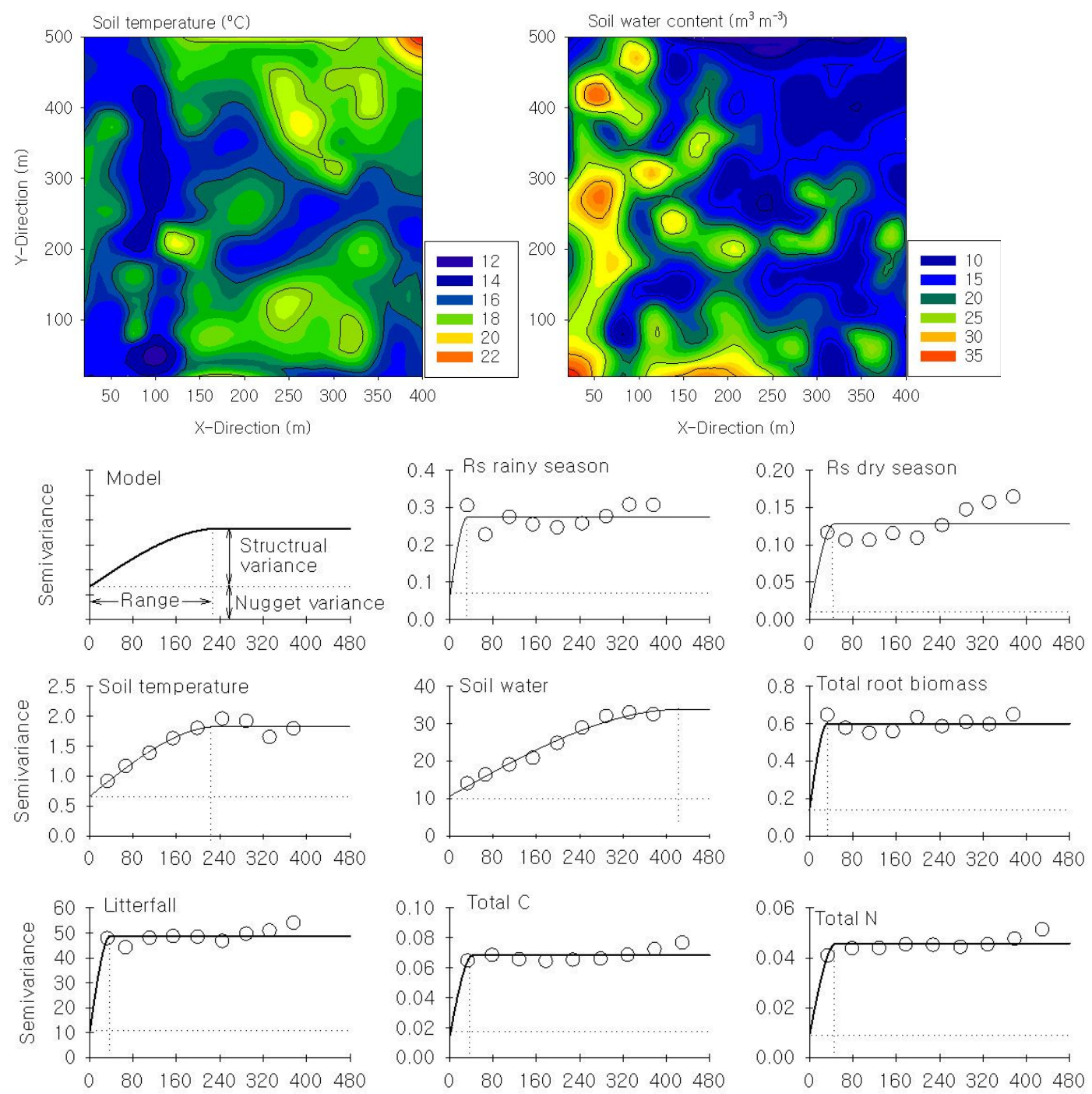

Fig. 4 - Variograms for soil respiration and related variables collected from the tropical rain forest of Xishuangbanna, China. A subplot tapped model was used to indicate the meaning of the variogram. The solid line represents the fitted spherical model (details of the fitted parameters were shown in a related table). The dashed line added to illustrate the ratio of the structural variance to nugget variance and the range at which autocorrelation existed.
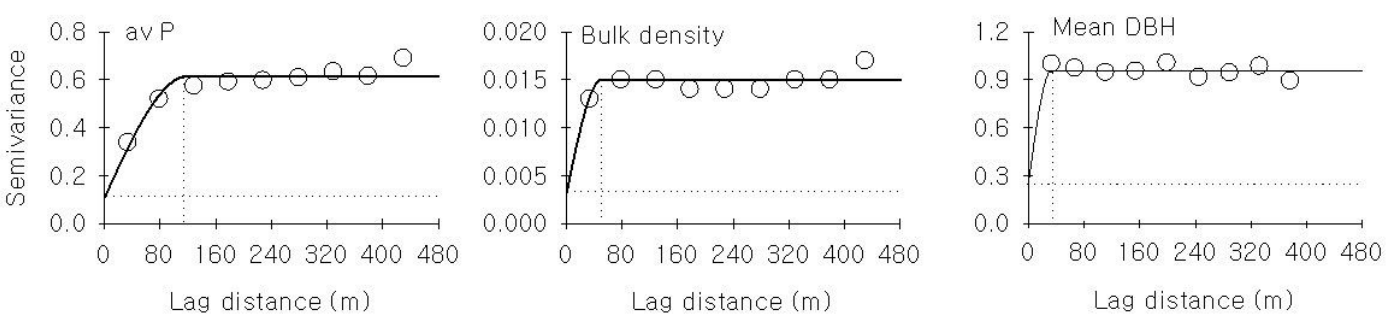
Tab. 2 - Parameters of the variogram spherical model for soil respiration in the rainy season $\left(\mathrm{R}_{\text {s-ain }}\right)$ and in the dry season $\left(\mathrm{R}_{\mathrm{s} \text {-dry }}\right)$, dry-season soil temperature at $5 \mathrm{~cm}\left(\mathrm{~T}_{\mathrm{s}-5}\right)$ and soil water content at $5 \mathrm{~cm}\left(\mathrm{M}_{\mathrm{s}-5}\right)$, mean diameter at breast height $(\mathrm{DBH})$, total root mass $\left(\mathrm{M}_{\text {root }}\right)$, litterfall production $\left(\mathrm{M}_{\mathrm{lf}}\right)$, total carbon content $(\mathrm{TC})$, total nitrogen content $(\mathrm{TN})$, available phosphorus content (avP), and bulk density $(\mathrm{BD})$. $\left(\mathrm{C}_{0}\right)$ : nugget variance; $\mathrm{C} /\left(\mathrm{C}_{0}+\mathrm{C}\right)$ : structural variance; (Range): the distance over which the structural variance is expressed; (D) fractal di mension under isotropic conditions.

\begin{tabular}{lcccc}
\hline Parameter & $\mathbf{C}_{\mathbf{0}}$ & $\mathbf{C} /\left(\mathbf{C}_{\mathbf{0}}+\mathbf{C}\right)$ & Range & D \\
\hline $\mathrm{R}_{\text {s-rain }}$ & 0.05 & 0.8 & 32.9 & 1.99 \\
$\mathrm{R}_{\text {s-dry }}$ & 0.01 & 0.92 & 45.4 & 1.93 \\
$\mathrm{~T}_{\text {s-5 }}$ & 0.66 & 0.64 & 240 & 1.85 \\
$\mathrm{M}_{\text {s-5 }}$ & 10.62 & 0.69 & 431.9 & 1.81 \\
$\mathrm{DBH}$ & 0.25 & 0.74 & 33.1 & 1.99 \\
$\mathrm{M}_{\text {root }}$ & 0.14 & 0.76 & 33.5 & 2 \\
$\mathrm{M}_{\text {lf }}$ & 10.3 & 0.79 & 43.4 & 1.98 \\
$\mathrm{TC}$ & 0.01 & 0.8 & 43.4 & 1.98 \\
$\mathrm{TN}$ & 0.01 & 0.8 & 49.7 & 1.97 \\
$\mathrm{avP}$ & 0.11 & 0.83 & 120 & 1.88 \\
$\mathrm{BD}$ & 0 & 0.8 & 51.9 & 1.97 \\
\hline
\end{tabular}

content were both normally distributed, with a skewness of around zero (Tab. 1). The average soil efflux of the termite mounds ranged from $1.63 \mu \mathrm{mol} \mathrm{m} \mathrm{m}^{-2} \mathrm{~s}^{-1}$ to $3.71 \mu \mathrm{mol} \mathrm{m} \mathrm{m}^{-2} \mathrm{~s}^{-1}$ (Tab. S1). When compared with the mean soil efflux of the entire 20-ha plot during the same period, the soil respiration above the termite mounds was lower.

The contour map of the soil respiration showed strong spatial heterogeneity during both the rainy and dry seasons (Fig. 3). The coefficient of variance (CV) of the soil effluxes was higher $(38-42 \%)$ than that of the soil water content $(28 \%)$ and temperature $(8 \%$ - Tab. 1), and this finding was confirmed by semivariogram analysis (Fig. 4). The range of autocorrelation for the soil respiration was 32-45 $\mathrm{m}$, which is far less than that of the soil temperature $(240 \mathrm{~m})$ and soil water content (431 m - Tab. 2). These fin- dings suggest that the patches of soil respiration are much smaller than those of soil temperature and water content. The differences in patch size can be illustrated well by a Kriging extrapolation map (Fig. S3). The patch sizes of the soil physical and chemical properties (i.e., total carbon and nitrogen content and bulk density) and stand parameters (i.e., mean diameter at breast height and litter fall production) were similar to those of soil respiration and varied between 30 and $50 \mathrm{~m}$, except for that of the available phosphorous (Tab. 2).

The linear correlation between the soil efflux during the dry and rainy seasons was not as strong as expected, indicating that the spatial pattern changed with time to a certain extent (Fig. 5a).

Stepwise multivariate regression rejected all of the studied variables to explain the spatial pattern of the soil respiration except soil temperature (Ts) and water content (Ws) $(\mathrm{Rs}=1.018-0.042 \mathrm{Ws}+0.151 \mathrm{Ts}, \mathrm{r}=0.347$, $\mathrm{p}<0.05, \mathrm{n}=151)$. The expected correlation between the stand structural parameters or soil properties and soil respiration was founded on the premise that the respiration measured in three soil collars could represent the $20 \times 20 \mathrm{~m}$ subplot as a whole. Using PCA, we found that the first principal component (PC1) accounted for $26 \%$ of the total variance (Tab. 3). PC1 was a combination of
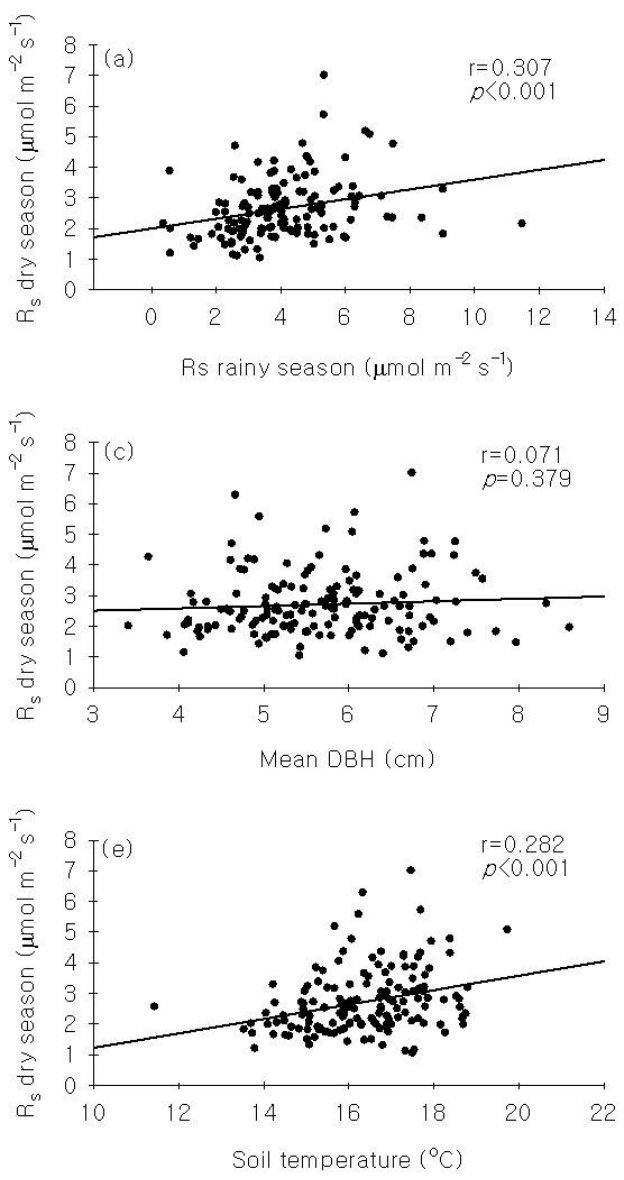

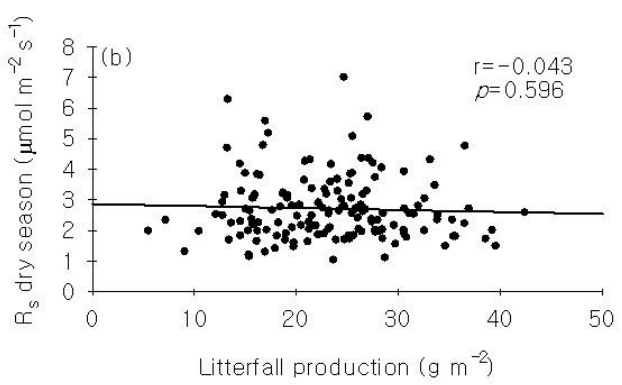

Fig. 5 - Relationship between soil respiration in the dry season and other related variables in a tropical rainforest of Xishuangbanna, China. The solid line is the linear regression line. 
Tab. 3 - Results of the principal components analysis. (§): Eigenvectors $>|0.30|$. Percents reflect the fraction of total variance accounted for by each principal component explained by various components of the PCA.

\begin{tabular}{lcc}
\hline Component & PC1 & PC2 \\
\hline Eigenvalues & 2.59 & 2.18 \\
Percent & 25.9 & 21.8 \\
Cumulative percent & 25.9 & 47.7 \\
Eigenvectors & & \\
$\mathrm{R}_{\text {s-rain }}$ & -0.29 & $0.36^{\S}$ \\
$\mathrm{R}_{\text {s-dry }}$ & $0.62 \S$ & 0.08 \\
$\mathrm{~T}_{\mathrm{s}-5}$ & $0.80 \S$ & 0.06 \\
$\mathrm{M}_{\text {s-5 }}$ & $-0.80^{\S}$ & -0.08 \\
$\mathrm{DBH}$ & 0.17 & 0.75 \\
$\mathrm{M}_{\text {root }}$ & -0.12 & $0.67 \S$ \\
$\mathrm{M}_{\mathrm{lf}}$ & -0.16 & $0.60 \S$ \\
\hline
\end{tabular}

microclimate factors, including the soil temperature at $5 \mathrm{~cm}$ and soil water content. The second principal component (PC2) accounted for an additional $22 \%$ of the total variance and represented variation in $\mathrm{DBH}$, root biomass and litter fall production (Tab. $3)$.

\section{Discussion}

Quantifying the spatial heterogeneity of soil respiration is a challenging matter that is commonly accomplished using the coefficient of variance (CV). Tedeschi et al. (2006) reported a CV of soil respiration ranging from $31 \%$ to $\sim 48 \%$ in Mediterranean forests. In a $30 \times 30 \mathrm{~m}$ plot of a larch plantation, 50 soil-respiration sampling points produced a CV of $28 \%$ (Yim et al. 2003). Moreover, a CV of $25 \%$ to $\sim 54 \%$ was found in a highly heterogeneous beech forest (Søe \& Buchmann 2005), while the spatial variability of soil respiration in perhumid Amazonian and Malaysian rainforests was characterized by a CV ranging from $24 \%$ to $\sim 45 \%$ (Sotta et al. 2004, Schwendenmann et al 2003 ) and from $26 \%$ to $\sim 62 \%$ (Kosugi et al. 2007, Katayama et al. 2009), respectively. The soil respiration of a strongly seasonal rainforest in Thailand showed a CV larger than 50\% (Adachi et al. 2009). For forests in which soil-respiration hot spots were detected, the CV was reduced to $41 \%$ to $\sim 59 \%$ (Ohashi et al. 2007, 2008). In the present study, the CV was found to be $42 \%$ and $38 \%$ in the rainy and dry seasons, respectively (Tab. 1). Overall, these results show that the spatial soil-respiration of forests generally varies between $20 \%$ and $50 \%$.

The range of autocorrelation depended on the sample size and temporal interval. Randomly placing ten soil collars in a $10 \times 10 \mathrm{~m}$ plot for soil respiration generated an autocorrelation range of $\sim 4.8 \mathrm{~m}$ (Tedeschi et al. 2006). Søe \& Buchmann (2005) reported an autocorrelation range of $\sim 6 \mathrm{~m}$ for soil respiration in a $72 \times 72 \mathrm{~m}$ plot with 144 soil collars. In a $2-\mathrm{m}$ grid $50 \times 50 \mathrm{~m}$ plot, the autocorrelation range varied from $4.4 \mathrm{~m}$ to 24.7 $\mathrm{m}$ (Kosugi et al. 2007). The average range of the spatial autocorrelation for soil respiration was $\sim 40 \mathrm{~m}$ in this study (Tab. 2).

Multiscale studies suggested that strong spatial heterogeneity exists at all scales (Williams et al. 2008, Martin \& Bolstad 2009, Lee et al. 2011). A small-scale $(<1 \mathrm{~m})$ assessment of spatial soil-respi ration variability in an agricultural area demonstrated a CV of 64\% (Stoyan et al. 2000). This result was supported by another study of a forest in Wisconsin that also showed considerable variation at scales $<1 \mathrm{~m}$ (Martin \& Bolstad 2009). At the landscape scale, the CV of soil respiration in space was $26 \%$ (Euskirchen et al. 2003). As an alternative and independent method, eddy covariance can be used to provide information regarding fluxes at larger scales; however, it cannot be used to depict small-scale spatial variations (Lee et al. 2011). We know less about soil respiration in spatial scales between small-scale chamber measurements and large-scale eddy flux observations; therefore, we sampled with an interval of $20 \mathrm{~m}$ in a 20 -ha rainforest plot in an attempt to address this gap. The soil-respiration heterogeneity (represented by the $\mathrm{CV}$ ) that we found was comparable to that of point-scale or landscape-scale measurements. A great deal of attention should be paid to patches with a size of $\sim 40 \mathrm{~m}$ when attempting to match the observations between the chamber method and the eddy covariance technique. Semivariance, which is a measure of dissimilarity (Rossi 1992), increased with distance to $40 \mathrm{~m}$ and then leveled off. These results suggest that the soil respiration was autocorrelated in the first $\sim 40 \mathrm{~m}$ patch and randomly distributed spatially above this threshold.

It is important to know which factors and mechanisms control the spatial pattern of soil respiration when attempting to scale up and predict patterns. An increasing number of studies have identified a close relationship between the structural parameters of a stand (e.g., mean DBH and basal area) and spatial patterns of soil respiration (Søe \& Buch- mann 2005, Katayama et al. 2009, Bréchet et al. 2011). In our studied forest, no spatial correlation between soil respiration and tree DBH was found $(r=0.071, p=0.379, n=151$ Fig. 5c). Additionally, no spatial correlation was observed between the soil respiration and other stand structural parameters (i.e., litter fall production and root biomass - Fig. 5b, Fig. 5d). In an Amazonian rainforest, the soil respiration was also not spatially correlated with stand structural parameters $(r=0.028, p=0.87, n=32$ - Sotta et al. 2004). Furthermore, three $10-\mathrm{cm}$ diameter samples did not represent a $20 \times 20 \mathrm{~m}$ uniform plantation with flat terrain (Xu \& Qi 2001), let alone a plot of the same size in a tropical rainforest with a strongly seasonal climate and complex terrain. The measurements of soil temperature and moisture were made in the same place as the soil respiration. Although soil temperature and water content play a leading role in controlling the temporal patterns of soil respiration, these factors are frequently found to be unable explain the spatial variation of soil respiration (Yim et al. 2003, Sotta et al. 2004, Tedeschi et al. 2006). In this study, we found only a slight correlation between the soil temperature or water content and soil respiration in the studied forest $\left(r^{2}<0.1-\right.$ Fig. 5e, Fig. $\left.5 f\right)$.

The number of samples required to estimate the mean soil respiration in our experiment using a modified equation (Davidson et al. 2002) was 71 and 51 for the rainy and dry seasons, respectively, with a $10 \%$ accepted error.

The soil respiration measured above termite mounds was not higher than the mean soil respiration, which coincided with the results of a previous study in a temperate forest (Ohashi et al. 2005). A systematic study of termite-mound soil respiration in the same forest also showed that termite mounds are not respiration hot spots (Schaefer D, personal communication, unpublished). Our experience is that the soil above termite mounds is particularly clayey and tightly packed, which hampers the diffusion of $\mathrm{CO}_{2}$ to the atmosphere. Termite nests may have unique features for gas outlets, which would result in large soil $\mathrm{CO}_{2}$ effluxes only being detected around these outlets. Another possible reason is that not all of the termites will remain in the nest all of the time. In the present study, all of the mounds that we selected had been abandoned by the termites.

\section{Conclusions}

Investigation of an entire 20-ha plot in a seasonal tropical rainforest revealed strong spatial heterogeneity in the rainy and dry seasons. The soil-respiration variability of this plot varied from $38 \%$ to $42 \%$. Additionally, there was no spatial correlation observed between soil respiration and tree $\mathrm{DBH}$, litterfall production or root biomass. 
The patch size of the soil respiration was approximately $40 \mathrm{~m}$. The biotic activity and additional physical parameters should be examined in future studies.

\section{Acknowledgments}

We thank Lang Ma, Jiu Ma, Xiao-Long Bai, and Jin-Xiang Xiong and Hong-Li Ji, Han-Mei Wang, and Lian-Yan Yang for their assistance in the field. Constructive comments by Jiao-Lin Zhang and Lu-Xiang Lin are gratefully acknowledged. This work was supported by Xishuangbanna Station for Tropical Rain Forest Ecosystem Studies (XSTRE). The study was funded by the $\mathrm{Na}$ tional Natural Science Foundation of China (41001063, 41071071), the Development Program in Basic Science of China (2010CB833501), the "Strategic Priority Research Program" of the Chinese Academy of Sciences (XDA05050601; XDA05050206) and the Chinese Academy of Sciences 135 program (XTBG-F01).

\section{References}

Adachi M, Ishida A, Bunyavejchewin S, Okuda T, Koizumi H (2009). Spatial and temporal variation in soil respiration in a seasonally dry tropical forest, Thailand. Journal of Tropical Ecology 25: 531-539. - doi: 10.1017/S026646740999006 $\mathrm{X}$

Allen SE (1989). Chemical analysis of ecological materials $\left(2^{\text {nd }}\right.$ edn $)$. Blackwell Scientific, Oxford, UK.

Arshad MA, Lowery B, Grossman B (1996). Physical tests for monitoring soil quality. Methods for assessing soil quality, Madison, WI, USA, pp. 123-141.

Bond-Lamberty B, Thomson A (2010). Temperature-associated increases in the global soil respiration record. Nature 464: 579-582. - doi: 10.1038/nature08930

Bréchet L, Ponton S, Alméras T, Bonal D, Epron D (2011). Does spatial distribution of tree size account for spatial variation in soil respiration in a tropical forest? Plant and Soil 347: 293-303. doi: 10.1007/s11104-011-0848-1

Cao M, Zhu H, Wang HH, Lan GY, Hu YH, Zhou SS, Deng XB, Cui JY (2008). Xishuangbanna tropical seasonal rainforest dynamics plot: tree distribution maps, diameter tables and species documentation. Yunnan Science and Technology Press, Kunming, China.

Davidson EA, Savage K, Verchot LV, Navarro R (2002). Minimizing artifacts and biases in chamber-based measurements of soil respiration. Agricultural and Forest Meteorology 113: 21-37. doi: 10.1016/S0168-1923(02)00100-4

Davidson RA, Belk E, Boone R (1998). Soil water content and temperature as independent or confounded factors controlling soil respiration in a temperate mixed hardwood forest. Global Change Biology 4: 217-227. - doi: 10.1046/j. 1365-2486.1998.00128.x

Euskirchen ES, Chen J, Gustafson EJ, Ma S (2003). Soil respiration at dominant patch types within a managed Northern Wisconsin landscape. Ecosystems 6: 595-607. - doi: 10.1007/ s10021-002-0167-8

Hanson PJ, Wullschleger SD, Bohlman SA, Todd DE (1993). Seasonal and topographic patterns of forest floor $\mathrm{CO}_{2}$ efflux from an upland oak forest. Tree Physiology 13: 1-15 - doi: 10.1093/ treephys/13.1.1

Katayama A, Kume T, Komatsu H, Ohashi M, Nakagawa M, Yamashita M, Otsuki K, Suzuki M, Kumagai T (2009). Effect of forest structure on the spatial variation in soil respiration in a Bonean tropical rainforest. Agricultural and Forest Meteorology 149: 1666-1673. - doi: 10.1016/j.agrformet.2009.05.007

Kosugi Y, Mitani T, Itoh M, Noguchi S, Tani M, Matsuo N, Takanashi S, Ohkubo S, Nik AR (2007). Spatial and temporal variation in soil respiration in a southeast Asian tropical rainforest. Agricultural and Forest Meteorology 147: 35-47. - doi: 10.1016/j.agrformet.2007.06.005

Lee H, Schuur EAG, Vogel JG, Lavoie M, Bhadra D, Staudhammer CL (2011). A spatially explicit analysis to extrapolate carbon fluxes in upland tundra where permafrost is thawing. Global Change Biology 17: 1379-1393. - doi: 10.1111/ j.1365-2486.2010.02287.x

Liang N, Nakadai T, Hirano T, Qu L, Koike T, Fujinuma Y, Inoue G (2004). In situ comparison of four approaches to estimating soil $\mathrm{CO}_{2}$ efflux in a northern larch (Larix kaempferi Sarg.) forest. Agricultural and Forest Meteorology 123: 97-117. - doi: 10.1016/j.agrformet.2003.10.002 Lundegårdh $H$ (1927). Carbon dioxide evolution of soil and crop growth. Soil Science 23: 417453. - doi: 10.1097/00010694-192706000-000 01

Martin JG, Bolstad PV (2009). Variation of soil respiration at three spatial scales: components within measurements, intra-site variation and patterns on the landscape. Soil Biology and Biochemistry 41: 530-543. - doi: 10.1016/j.soilbio. 2008.12.012

Ma TS, Zuazaga G (1942). Micro-Kjeldahl determination of nitrogen. A new indicator and an improved rapid method. Industrial and Engineering Chemistry $14: 280-282$

Nelson DW, Sommers LE (1996). Total carbon, organic carbon, and organic matter. In: "Methods of Soil Analysis: Part 3-Chemical Methods" (Sparks DL et al. eds). SSSA Book Series No. 5, Soil Science Society of America, Madison, WI, USA, pp. 961-1010.

Ohashi M, Kume T, Yamane S, Suzuki M (2007). Hot spots of soil respiration in an Asian tropical rainforest. Geophysical Research Letters 34: L08705. - doi: 10.1029/2007GL029587

Ohashi M, Finér L, Domisch T, Risch AC, Jurgensen MF (2005). $\mathrm{CO}_{2}$ efflux from a red wood ant mound in a boreal forest. Agricultural and Forest Meteorology 130: 131-136. - doi: 10.1016/j.agrformet.2005.03.002

Ohashi M, Kumagai T, Kume T, Gyokusen, K, Saitoh TM, Suzuki M (2008). Characteristics of soil $\mathrm{CO}_{2}$ efflux variability in a seasonal tropical rainforest in Borneo Island. Biogeochemistry 90:
275-289. - doi: 10.1007/s10533-008-9253-0

Raich JW, Schlesinger WH (1992). The global carbon dioxide flux in soil respiration and its relationship to vegetation and climate. Tellus 44 (B): 81-99. - doi: 10.1034/j.1600-0889.1992.t011-00001.x

Rayment MB, Jarvis PG (2000). Temporal and spatial variation of soil $\mathrm{CO}_{2}$ efflux in a Canadian boreal forest. Soil Biology and Biochemistry 32: 35-45. - doi: 10.1016/S0038-0717(99)00110-8 Robertson GP, Crum JR, Ellis BG (1993). The spatial variability of soil resources following long-term disturbance. Oecologia 96: 451-456. doi: 10.1007/BF00320501

Rossi R (1992). Geostatistical tools for modelling and interpreting ecological spatial dependence. Ecological Monographs 62: 277-314. - doi: $10.2307 / 2937096$

Saghir NS, Mungwari FP, Mulvaney RL, Azam F (1993). Determination of nitrogen by microdiffusion in mason jars. II. Inorganic nitrogen-15 in soil extracts. Communications in Soil Science and Plant Analysis 24: 2747-2763. - doi: 10.1080/00103629309368993

Schwendenmann LC, Veldkamp E, Brenes T, O'Brien JJ, Mackensen J (2003). Spatial and temporal variation in soil $\mathrm{CO}_{2}$ efflux in an oldgrowth neotropical rain forest, La Selva, Costa Rica. Biogeochemistry 64: 111-128. - doi: 10.1023/A:1024941614919

Sha LQ, Zheng Z, Tang JW, Wang YH, Zhang YP, Cao M, Wang R, Liu GR, Wang YS, Sun Y (2005). Soil respiration in tropical seasonal rain forest in Xishuangbanna, SW China. Science in China, Ser D 48: 189-197. - doi: 10.1360/05zd 0019

Søe ARB, Buchmann N (2005). Spatial and temporal variations in soil respiration in relation to stand structure and soil parameters in an unmanaged beech forest. Tree Physiology 25: $1427-$ 1436. - doi: 10.1093/treephys/25.11.1427. Sotta ED, Meir P, Malhi Y, Nobre AD, Hodnett $\mathrm{M}$, Grace J (2004). Soil $\mathrm{CO}_{2}$ efflux in a tropical forest in the central Amazon. Global Change Biology 10: 601-617. - doi: 10.1111/j.15298817.2003.00761.x

Stoyan H, De-Polli H, Böhm S, Robertson GP, Paul EA (2000). Spatial heterogeneity of soil respiration and related properties at the plant scale. Plant and Soil 222: 203-214. - doi: 10.1023/ A: 1004757405147

Tan ZH, Zhang YP, Yu GR, Sha LQ, Tang JW, Song QH (2010). Carbon balance of a primary tropical seasonal rain forest. Journal of Geophysical Research 115: D00H26. - doi: 10.1029/ 2009JD012913

Tedeschi V, Rey A, Manca G, Valentini V, Jarvis PG, Borghetti M (2006). Soil respiration in a Mediterranean oak forest at different developmental stages after coppicing. Global Change Biology 12: 110-121. - doi: 10.1111/j.13652486.2005.01081.x

Williams M, Bell R, Spadavecchia L, Street LE, Wijk MT (2008). Upscaling leaf area index in an Arctic landscape through multiscale observations. Global Change Biology 14: 1517-1530. - 
doi: 10.1111/j.1365-2486.2008.01590.x

Xu M, Qi Y (2001). Soil-surface $\mathrm{CO}_{2}$ efflux and its spatial and temporal variations in a young ponderosa pine plantation in northern California. Global Change Biology 7: 667-677. - doi: 10.1046/j.1354-1013.2001.00435.x

Yao YG, Zhang YP, Yu GR, Sha LQ, Deng Y, Tan ZH (2011). Representative time selection analysis on daily average value of soil respiration in a tropical rain forest. Journal of Nanjing Forestry University (Natural Science Edition) 35 74-78. - doi: 10.3969/j.issn.1000-2006.2011.04. 015

Yim MH, Joo SJ, Shutou K, Nakane K (2003). Spatial variability of soil respiration in a larch plantation: estimation of the number of sampling points required. Forest Ecology and Management 175: 585-588. - doi: 10.1016/S0378-1127(02) 00222-0

\section{Supplementary Material}

Tab. S1 - Soil respiration rate measured above termite nest in the Xishuangbanna tropical seasonal rainforest. Units are $\mu \mathrm{mol}$ $\mathrm{m}^{-2} \mathrm{~s}^{-1}$.

Fig. S1 - The $400 \times 500 \mathrm{~m}$ plot was divided into 500 subplots of $20 \times 20 \mathrm{~m}$. Some 151 (dashed squares) of the 500 subplots were selected for litterfall collection and soil respiration measurements.

Fig. S2 - The temporal variance of soil respiration (a), soil temperature at $5 \mathrm{~cm} \mathrm{(b)} \mathrm{and}$ soil water content at $5 \mathrm{~cm}$ (c) monitored by an automatic respiration measurement system developed by one of the authors of this study - Dr. Naishen Liang.
Fig. S3 - Kriging maps based on semivariance analysis showing the spatial variance of the following parameters: (a) soil respiration in the rainy season ; (b) soli respiration in the dray season; (c) soil temperature in the dry season; (d) soil water content in the dry season. Soil respiration is expressed in $\mu \mathrm{mol}$ $\mathrm{m}^{-2} \mathrm{~s}^{-1}$, soil temperature is in Celsius degrees, soil water content is in $\mathrm{m}^{3} \mathrm{~m}^{-3}$.

Fig. S4 - Contour maps of the stand parameters in a tropical rainforest of Xishuangbanan, China.

Fig. S5 - Contour maps of the soil and chemical properties of a tropical rainforest of Xishuangbanan, China.

Link: Tan_681@supp1001.pdf 